\title{
Evaluation of the wear characteristics of three different materials used for provisional implant-supported restorations
}

\author{
Aswana Jaiprakash, Jayakrishnakumar Sampathkumar, Chitrashankar Krishnan, \\ Hariharan Ramasubramanian, Hariharan Ramakrishnan, Rahmath Shameem, \\ Nagarasampatti Sivaprakasam Azhagarasan \\ Department of Prosthodontics \& Implantology, Ragas Dental College \& Hospital, Tamilnadu, India
}

Purpose: This study was conducted to comparatively evaluate the wear resistance of three different materials used for provisional implant-supported restorations.

\begin{abstract}
Materials and Methods: Thirty natural mandibular first premolar teeth were considered as antagonist teeth specimens. Ten samples each of milled polymethylmethacrylate (milled PMMA, Group I), milled polyetheretherketone (milled PEEK, Group II), and indirect composite resin (SR ADORO, Group III) were designated as disc samples. The samples were subjected to a wear test in a pin-on-disc machine. The surface roughness, wear rate, coefficient of friction, and volume loss were measured after wear testing. The results were analyzed using a paired ' $t$ ' test, analysis of variance, and the post-hoc Tukey's Honestly Significant Difference (HSD) analysis. Scanning electron microscopic analysis was done for one representative tested sample from each test group.
\end{abstract}

Results: Mean surface roughness (Ra) values before and after the wear test for Groups I, II and III were $0.827 \mu \mathrm{m}, 6.021 \mu \mathrm{m}, 0.473 \mu \mathrm{m}$, and $1.194 \mu \mathrm{m}, 0.455 \mu \mathrm{m}$ and $1.407 \mu \mathrm{m}$ respectively. Mean wear rates $(\mathrm{mg} / \mathrm{min})$ of Groups I, II \& III were 0.000, 0.010, and 0.011, respectively. Mean coefficients of friction ( $\mu$ ) of Groups I, II \& III were $0.979,0.864$, and 0.840, respectively. Mean volume losses (mm3) of Groups I, II \& III were 6.709, 7.726, and 5.244, respectively. Scanning electron microscopic analysis revealed a prominently roughened surface for Group I, a moderately roughened surface for Group III, and a smoother surface for Group II. The milled polymethylmethacrylate exhibited significantly higher surface roughness both before and after the wear test as compared to both the milled polyetheretherketone and composite materials, which was corroborated by surface profilometry and scanning electron microscopic analysis.

Conclusions: Milled polymethylmethacrylate showed significantly higher wear as compared to the other two materials indicative of it having the least wear resistance among the test materials. Milled polyetheretherketone exhibited a marginally smoother surface compared to the composite material. Milled polyetheretherketone and the composite showed marginal differences in wear resistance, which was statistically insignificant, indicative that these two test materials had a similar wear resistance. (JOURNAL OF DENTAL IMPLANT RESEARCH 2021;40(3):97-106)

Key Words: Polymethylmethacrylate, Polyetheretherketone, Composite dental resin, Restoration occlusal wear, Friction, Dental implant

\section{INTRODUCTION}

The predictable nature of osseointegrated dental im- plants has revolutionised the rehabilitation of edentulous patients. Clinical studies have shown a success rate of more than $90 \%$ with endosseous dental implants ${ }^{1,2}$.

Received July 7, 2021, Revised August 6, 2021, Accepted August 11, 2021.

(c) Journal of Dental Implant Research.

This is an open access article distributed under the terms of the Creative Commons Attribution Non-Commercial License

(http://creativecommons.org/licenses/by-nc/4.0) which permits unrestricted non-commercial use, distribution, and reproduction in any medium, provided the original work is properly cited.

Correspondence to: Jayakrishnakumar Sampathkumar, https://orcid.org/0000-0003-0047-1999

Department of Prosthodontics \& Implantology, Ragas Dental College \& Hospital, Uthandi, Chennai 600119, Tamilnadu, India. Tel: +04424530006, Fax: +04452123995, E-mail: jayakrishnakm@yahoo.com

Our heartfelt gratitude to Pro Vice Chancellor Dr. Narayanan, Dr. Geetha Manivasagam, Department of Center for Biomaterials Sciences and Technology, and the staff of the mechanical engineering, Vellore Institute of Technology, Vellore, Tamilnadu, India for their support. We would also like to thank staff members in Department of Manufacturing Engineering, Anna University, Chennai, India for their valuable support. 
Specific implant case scenarios warrant an extended time duration before the insertion of the definitive prosthesis, such as, delay in the maturity of the soft tissue surrounding the implant platform, which is essential for a good emergence profile, bone augmentation sites, require considerable time before the fabrication of final prosthesis, to allow the favourable bone to implant contact ${ }^{1,3,4)}$. good aesthetic results are of paramount importance for the successful outcome of implant restorations, and this requires ideal soft-tissue maturation which should be in harmony with the periodontal tissues of the adjacent teeth ${ }^{1,5,6)}$.

The role of a provisional prosthesis is crucial in implant prosthodontics as it allows for proper contouring of the gingival soft tissues. An anatomically contoured provisional restoration is to achieve harmonious peri-implant soft tissue and also to determine the type of occlusal scheme in the final prosthesis ${ }^{5}$. Provisional restorations termed as short term or long term restorations. The duration for which they need to remain in place is dependent on the implant site preparation before implant placement, the loading protocol and the soft tissue contouring. The average time of an implant-supported provisional restoration is usually three months, but it is prolonged if an extended evaluation period is required. Nowadays, the implant is placement, keeping in mind the position and requirements of the final restoration ${ }^{1,6)}$.

Long term provisional's arc preferred mainly due to their superior strength and esthetics offered by these materials. The provisional materials used in the laboratory include heat-cured polymethylmethacrylate resin (PMMA), indirect laboratory composites and more recently, CAD-CAM milled PMMA and Polyetheretherketone (PEEK) materials ${ }^{7,8}$. Traditionally, heat-cured PMMA widely used in the construction of interim restorations due to their ease of manipulation and low cost. However, they exhibit clinical disadvantages like polymerisation shrinkage, low wear resistance and colour instability. Millable PMMA materials reportedly overcoming these drawbacks ${ }^{1)}$.

High-density polymers based on highly cross-linked PMMA or composite resins have gained interest recently. CAD/CAM blocks are polymerised at high temperature and pressure under controlled conditions resulting in consistent chemical and mechanical properties than manually polymerised blocks ${ }^{9}$. Their mechanical properties such as flexural strength are comparable to glass-ceramics, making them a favourable long term provisional implant-supported restorative material. Also, no substrate is required for reinforcement. Milling high-density polymers to complete contour restorations simplifies the production process.

The novel high-performance composite polyetheretherketone (PEEK), with its favourable mechanical properties, is a polymer form of polyaryletherketone (PAEK) is available in both granular form and milled blanks. Stawarczyk et al. reported a mean load-bearing capacity of $1383 \mathrm{~N}$ for a three-unit PEEK fixed dental prosthesis (FDP), suggesting the use of PEEK as a suitable material for this purpose ${ }^{8)}$. However, there are some drawbacks, in that; aesthetics limit the use of PEEK as full coverage monolithic restorations. Due to its excellent physical and mechanical properties, this material is used both in medicine and dentistry as an implant, provisional abutment and implant supported-bar or clamp material. Besides, CAD/CAM milled blanks, after industrial fabrication under optimal conditions display a reduced risk of porosities within the restoration and therefore considered for a long term provisional restorative material ${ }^{8-10}$.

Indirect composite resin-based restorations have become an alternative to acrylic based restorations for the functional aesthetic treatment of posterior teeth as both definitive and provisional restorations. They are essentially a composite resin matrix with different filler components. One of the available micro filled composite system developed for this purpose, offers distinct advantages in terms of handling, surface texture and wear. The resin matrix incorporates a newly developed aromatic-aliphatic urethane di methacrylate (UDMA) whose toughness is superior to that of other monomers. Also, the inorganic filler content of the material is responsible for its superior properties ${ }^{11}$.

An essential prerequisite for the successful assessment of implant-supported provisional restorations is the wear resistance of the provisional materials employed. Wear of the material is influenced by numerous factors including contact, geometry, surface roughness, microstructural features, fracture toughness, velocity, load, temperature, duration, environment and lubrication ${ }^{12)}$. Occlusal wear results in alterations in the surface texture of the substrate 


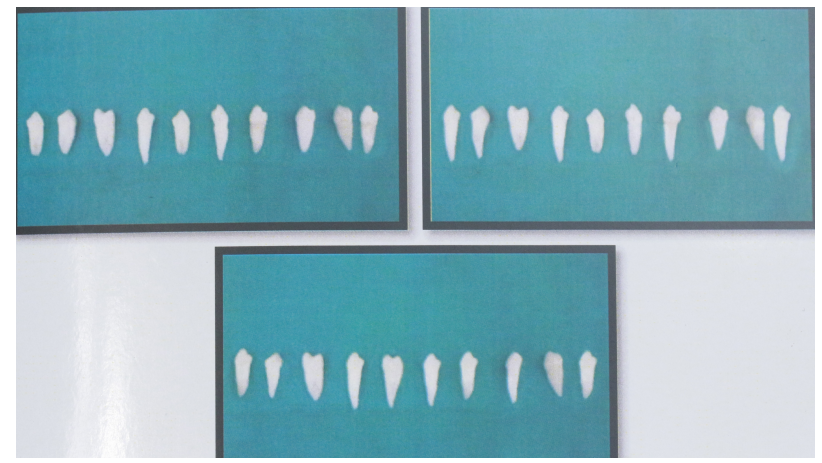

Fig. 1. Natural teeth specimens-mandibular first premolars (thirty).

material. Changes in the surface roughness/topography, favours the formation of biofilm, leading to inadequate oral hygiene maintenance and eventually causes chipping or fracture of the restoration ${ }^{12)}$.

A sensitive method to study differences in the structural integrity of a dental restorative material is by determination of wear using a two-body wear test - two-body abrasion results in surfaces that are rubbed away from direct contact. In the mouth, these conditions occur predominantly during non-masticatory tooth movement ${ }^{13)}$. There are several testing methods capable of analysing two-body wear patterns between different biomaterials such as pin-on-disc, reciprocating ball and crater, twin $\operatorname{disc}^{14)}$. Tribological wear process refers to the presence of a "third body" between the teeth and their opposing restorations during mastication ${ }^{13)}$. Many authors have suggested the use of pin-on-disc as one of the most reliable methods to evaluate wear. These in vitro wear tests are conducted to simulate a particular duration of clinical use by setting a fixed number of wear cycles in the testing equipment ${ }^{13)}$. Pin-on-disc wear testing is a method of quantitatively evaluating the rate of wear, coefficient of friction, and volume loss of material between two materials. This tribological test can simulate multiple modes of wear including unidirectional, bidirectional and omnidirectional forces ${ }^{9,11)}$.

Dental interest in CAD/CAM provisional materials has increased due to its higher fracture resistance, better stress distribution and lower abrasion of the antagonist enamel ${ }^{15)}$. Previous studies have evaluated the tribological behaviour for conventional composite resins and dental ceramics. Studies evaluating the wear of CAD/CAM polymers used as a provisional ISPR material

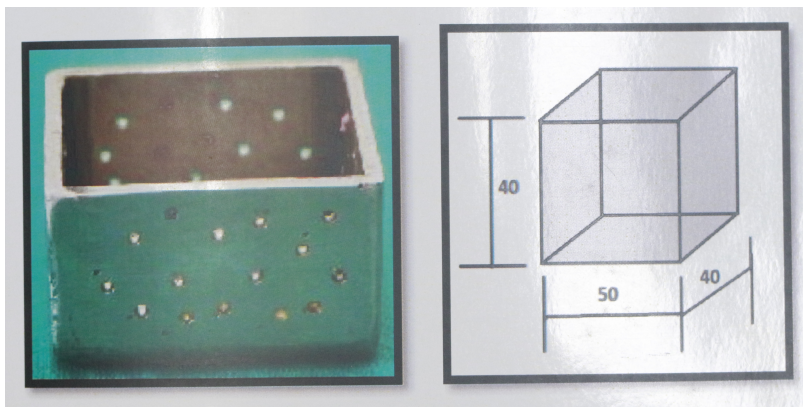

Fig. 2. Stainless steel metal mould.

are very few. The applications of PEEK as an interim material for implant-supported crowns are still in its early stages and data of its wear behaviour is sparse ${ }^{8)}$. Since the wear behaviour of the long term provisional material is essential for the durability of the implant-supported restorations, the tribological behaviour of these materials needs further evaluation. Further, comparative in vitro studies evaluating the wear behaviour of CAD/CAM milled PMMA, PEEK and indirect composites are in one single study are lacking.

Therefore, the present in vitro study was conducted to comparatively evaluate the wear resistance of three different materials used for provisional implant-supported restorations. The null hypothesis of the present study is that the wear testing will not result in significantly different wear outcomes for the three test materials.

\section{MATERIALS AND METHODS}

Thirty extracted human mandibular first premolar (Fig. 1) free of dental caries are used for this study. The extracted teeth are soaked in hydrogen peroxide in order to remove and clean debris and then stored in desiccators for further use. For wear testing in a pin-on-disc machine, the natural tooth is utilised as a pin. A square-shaped stainless steel metal mould measuring $40 \mathrm{~mm} \times 40 \mathrm{~mm} \times 40$ mm (Fig. 2) is fabricated to serve as a matrix for holding the putty material. This serves in holding the cylindrical metal insert measuring $10 \mathrm{~mm} \times 40 \mathrm{~mm}$ (Fig. 3) in the centre of the putty, which enables the fabrication of pin for the testing.

Addition silicone is mixed, and the stainless-steel metal mould is filled with it. To obtain a PMMA pin holder, a cylindrical metal insert of $10 \mathrm{~mm} \times 40 \mathrm{~mm}$ was posi- 


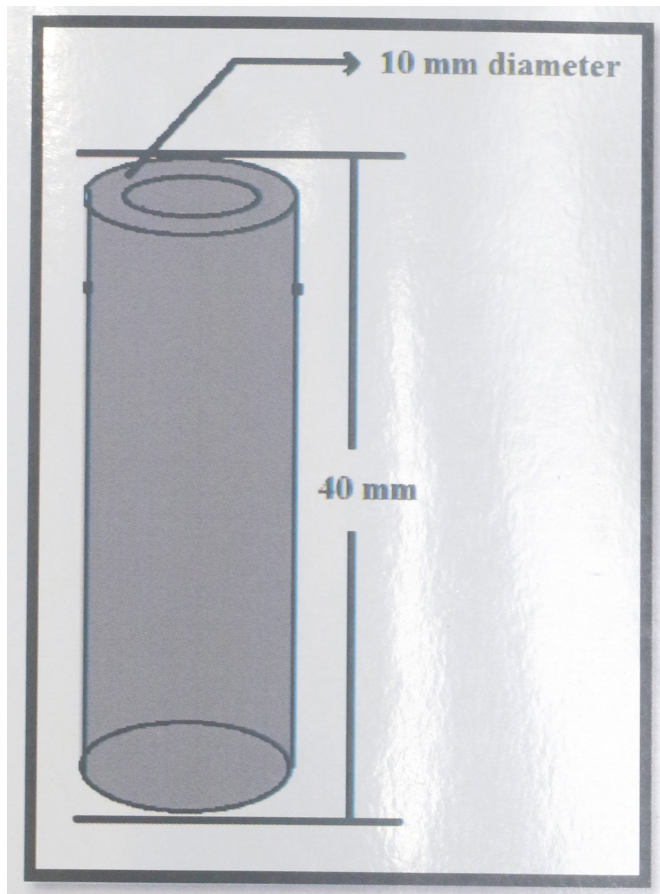

Fig. 3. Cyclindrical insert.

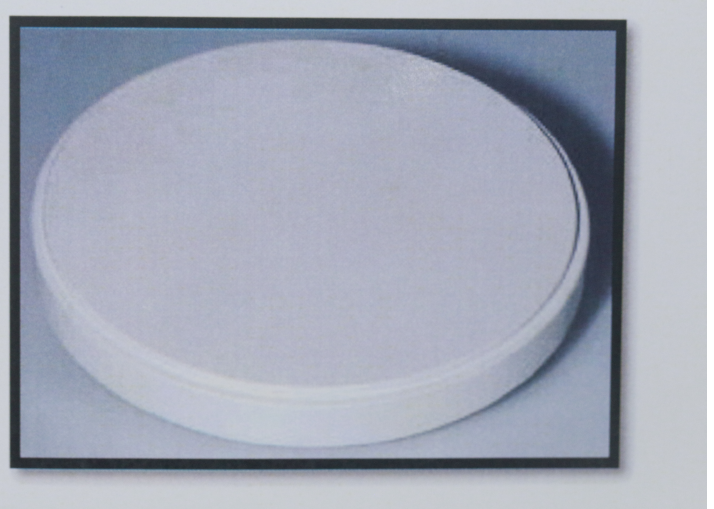

Fig. 4. CAD CAM PMMA blank.

tioned in the centre of the putty material and allowed to set. Once the putty sets, the cylindrical metal insert was removed, and the core is formed. The auto polymerising PMMA resin is mixed to correct consistency and poured into the cavity opening, and at the same time, the tooth is also positioned. Care is taken to ensure that the tooth is at vertical and right angles to the PMMA holder. Now the required tooth is impregnated and ready to use with wear testing machine. The lingual cusp is reduced to $3 \mathrm{~mm}$ with a sandpaper disc. This is done to achieve a single point contact only through the buccal cusp and eliminated multiple contacts, which can increase the fric-

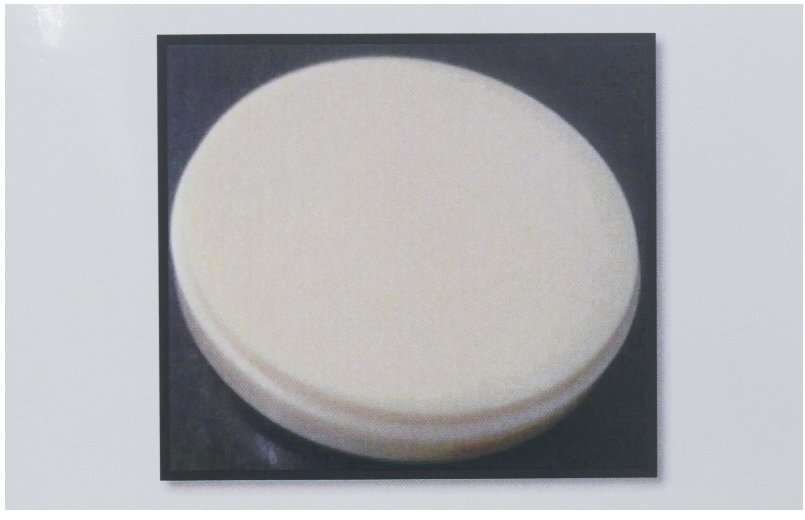

Fig. 5. CAD CAM PEEK blank.

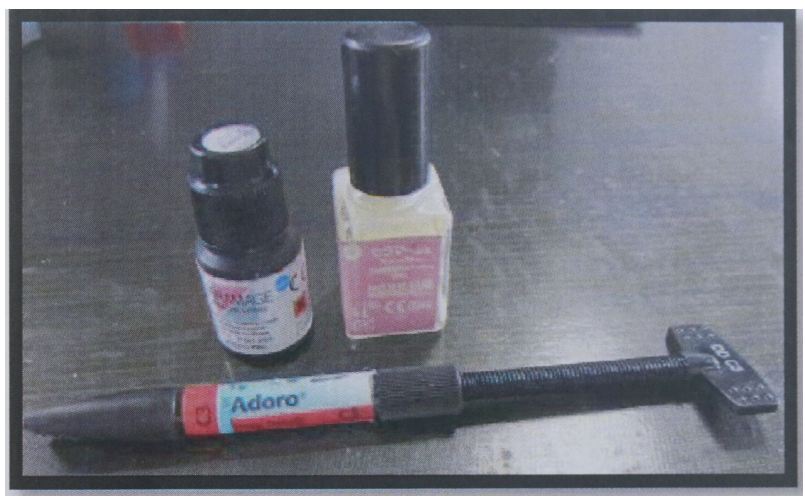

Fig. 6. SR Adoro composite resin.

tion between the pin material and disc material.

A total of 30 mandibular first premolar natural teeth are processed as pins for wear test against the provisional materials used in this study. This stainless-steel metal disc measuring $20 \mathrm{~mm} \times 5 \mathrm{~mm}$ is utilised to mill the CAD PMMA blank (Fig. 4) and CAD PEEK blank to the size of a metal disc. A template of $20 \mathrm{~mm}$ diameter $\times 5 \mathrm{~mm}$ thickness for the CAD PMMA blank to be milled are transferred as STL file to a CAM software. This data is then sent to the milling centre, and a five-axis milling machine milled CAD PMMA test samples. From one blank of CAD PMMA, 10 test samples $(n=10)$ were generated.

A template of $20 \mathrm{~mm}$ diameter $\times 5 \mathrm{~mm}$ thickness for the CAD PEEK blanks (Fig. 5) to be milled transferred as STL file to a CAM software. This data was then sent to the milling centre, and a five-axis milling machine milled CAD PEEK test samples. From one blank of CAD PEEK, 10 test samples $(n=10)$ are generated. A metal die measuring $20 \mathrm{~mm} \times 5 \mathrm{~mm}$ having a flat and polished base is used in the fabrication of the SR Adoro discs. 
For SR Adoro (Fig. 6) test sample, a metal die is made measuring $20 \mathrm{~mm} \times 5 \mathrm{~mm}$ with polished base plate at the bottom of the die. A layer of deep dentin Adoro material was added into the die and appropriately positioned to high-performance Lumamat 100 heat furnace for optimum polymerisation/tempering for $1 \mathrm{~min}$ (for hardening the material) so that they can develop their physical properties to its fullest. Similarly, the material was added layer by layer to the desired thickness. Modelling liquid is added to adjust the consistency of the material and tempered for $1 \mathrm{~min}$. Finally, light-curing did for $15 \mathrm{~min}$, and Adoro disc obtained. Similarly, 10 Adoro discs are generated.

A total of thirty test samples from three different provisional restorative materials used for the present study. These different samples were subjected to very fine shaping and finishing with increasing grades of corundum coated paper with grits from 100, 120, 180, 220, 320. polishing was achieved with last two grits. Milled PMMA test samples listed as Group I $(n=10)$. Milled PEEK test samples listed as Group II $(n=10)$. SR Adorn test samples listed as Group III $(n=10)$. These test samples prepared for wear testing. To one litre de-ionised water, $0.65 \mathrm{~g} / \mathrm{li}-$ tre of potassium chloride, $0.058 \mathrm{~g} /$ litre of magnesium chloride, $0.165 \mathrm{~g} /$ litre of calcium chloride, $0.804 \mathrm{~g} /$ litre of di-potassium hydrogen phosphate, $0.365 \mathrm{~g} /$ litre of potassium dihydrogen phosphate, $2 \mathrm{~g}$ /litre of sodium carboxyl methylcellulose added and dissolved to obtain artificial saliva. The test samples are soaked in saliva solution 24 hours before to simulate the oral conditions and to have a thin film of saliva over the surface of the discs.The test samples of all the three groups were weighed individually before and after wear testing procedure using a microbalance procedure. Weight of each sample is expressed in milligrams, and these values aid in the calculation of the wear rate of the test material.

The test samples of all the three groups were subjected individually to 3-D surface profile scanning before and after wear testing. 3-D surface roughness was measured using a 3-D non-contact profilometer. The average surface roughness $(\mathrm{Ra})$ value of each sample is obtained. The magnification of the optical lens \& pictographs is at $50 \times$. Each sample is placed under the objective lens and observed at 50× magnification to obtain 3-D and advanced

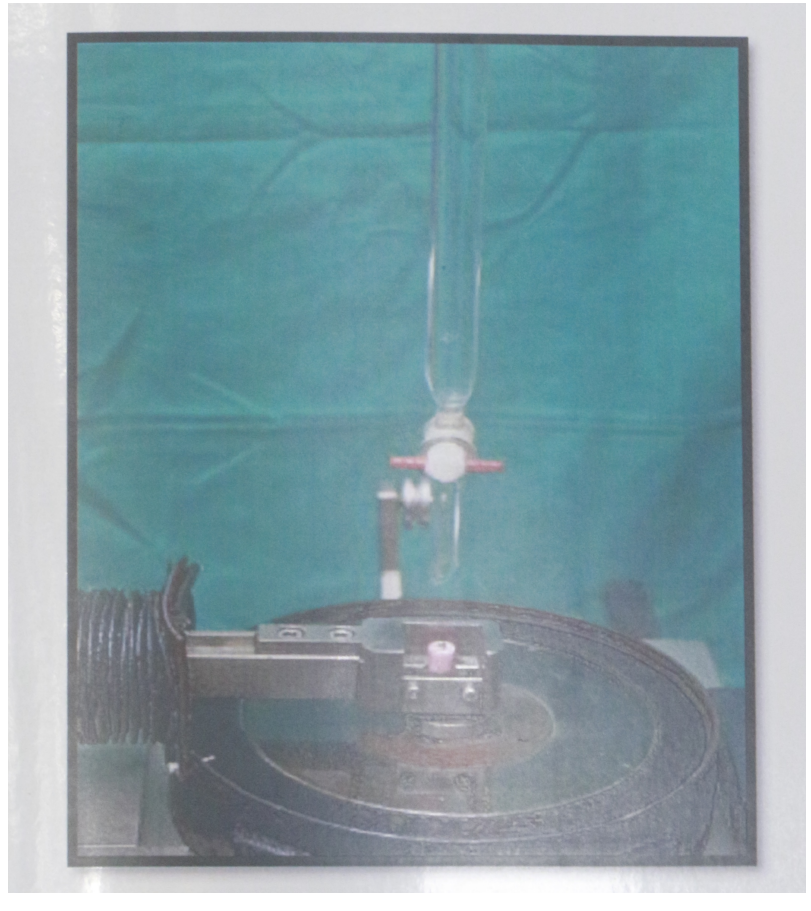

Fig. 7. Pin on disc testing machine.

3-D views using Advanced Aspherics Analysis Software. A stainless steel metal circular mould disc measuring 34 $\mathrm{mm} \times 8 \mathrm{~mm}$ dimension made. On one side of the circular disc, a mould is made with a dimension of $20 \mathrm{~mm} \times 5 \mathrm{~mm}$ to hold the disc sample material. On the other side, an ejection screw is made to fit into the revolving disc of the wear testing machine (Pin-on-disc machine).

The test sample is removed from artificial saliva after 24 hours of storage, was positioned on to the customised metal mould disc. The mould disc, along with the test sample, was placed on the revolving disc of the wear testing machine (Pin-on-disc machine). The pin/tooth is placed into the pin holder, and the clamp screws are tightened to avoid slipping during the loading and rotation of the disc. The pin was then adjusted so that the tooth would have a point of contact against the disc sample by adjusting the track diameter to $10 \mathrm{~mm}$ (Fig. 7). The respective screws are tightened for the pin and the disc. Each test sample subjected to 5000 wear cycles at 750 RPM. The period required to fulfil these cycles and RPM calculated using the following formula.

Time in sec: (sliding distance in $\mathrm{mm}^{*} 60000 / 3.14^{*}$ sliding dia in $\mathrm{mm}^{*}$ R.P.M). This calculated time was found to be 6 minutes and 32 seconds and was kept uniform 
for wear testing of all the test samples used in this study. The above mentioned parameters (wear cycles, RPM, time duration and the load=25 N) are set in the control panel of the wear testing machine, and the testing is conducted individually for all the 30 test samples (test samples of Group I, Group II and Group III). The entire procedure of wear testing carried out under the constant flow of artificial saliva.. After the completion of the wear testing of each test sample, it is removed from the testing apparatus. The wear track width of each test sample of the three test groups is measured individually using a Vernier calliper, and the measurements obtained in millimetres (mm). These measurements used to calculate the volume loss for each test samples in the present study.

One representative tested a sample from each test group was randomly selected and subjected to qualitative SEM examination (Jeol, JSM- 6390LA). The samples secured into copper $(\mathrm{Cu})$ stubs with double adhesive tape and coated with a layer of gold using the gold sputtering system. Coated samples examined under SEM to qualitatively assess the surface topography of disc samples at $250 \times$ and $500 \times$ magnification.

\section{RESULTS}

Mean surface roughness $(\mathrm{Ra}, \mu \mathrm{m})$ values before and after wear test for GROUPS I, I and III were 0.827, 6.021, $0.473,1.194,0.455$ and 1.407 respectively. Mean wear rates $(\mathrm{mg} / \mathrm{min})$ of GROUPS I, II \& II were $0.000,0.010$ and 0.011 , respectively. Mean coefficients of friction $(\mu)$ of Groups I, II \& III were 0.979, 0.864 and 0.840, respectively. Mean volume loss (mm) of groups I, II \& III were $6.709,7.726$ and 5.244, respectively. SEM analysis under $250 \times$ and $500 \times$ magnifications, revealed predominantly microroughened and frosty surface under 250×, and under $500 \times$ revealed frosty areas with well defined peaks and valleys distributed throughout the surface indicative of greater surface roughening in group I samples. For group II samples under 250×, there was predominantly smooth surface with sparsely distributed elevations, and under 500× elevations appeared sparsely distributed with poorly defined peaks indicative of smoother surface. For group III samples under $250 \times$, there was uniformly distributed microroughened surface and under
$500 \times$, these microroughened patches were of moderately defined peak and valleys, indicative of moderate roughened surface. statistical analysis performed using One way ANOVA and posthoc Tukey HSD analysis (SPSS-16, California, USA).

\section{DISCUSSION}

Long term success of an Implant-Supported Restoration depends not only on the expertise of the operator but also on the nature and properties of biomaterials involved in the fabrication of the restoration. Due to the dynamic nature of the stomatognathic system, the materials employed in the fabrication of long term provisional restoration should possess specific prerequisites such as hardness, flexural strength and wear resistance for a predictable functioning ${ }^{1,5,6)}$.

With the advent of CAD/CAM technology, milling of dental materials have been made possible for various applications. CAD/CAM polymers which can be processed more rapidly and at a lower cost are slowly replacing the conventional impression-model fabrication technique. The superior technical properties exhibited by the milled resins is attributed to the method of polymerisation. The resin blanks are processed at a higher temperature and pressure under optimal conditions than the manually polymerised blanks ${ }^{1)}$. Milled PMMA contains $99.5 \%$ of the homogeneous polymer, and a very low residual monomer undergoes complete conversion into a high-density polymer, and this seems to offer useful material properties as there is no need for fibre reinforcement or any substructure ${ }^{16}$. Studies demonstrating the wear characteristics of milled PMMA for long term provisionalisation are sparse in the literature.

Currently, titanium and its alloys are used as dental implant biomaterial. Despite its significant advantages, few disadvantages such as the dark greyish colour of the abutment cause aesthetic incompatibility which paved the way for the search of newer metal-free restorations ${ }^{17)}$.

Advancement in biomedical research and processing techniques have to lead to the production of new biomaterial polyetheretherketone (PEEK). It is a high-performance thermoplastic polymer consisting of an aromatic backbone molecular chain interconnected by ether 
and ketone functional groups ${ }^{8,10,17)}$. Due to its excellent physical properties, this material is used both in general medicine and dentistry as an implant, provisional abutment, implant-supported bar or clamp material. With regards to implant-supported provisional restoration, PEEK biomaterial offers superior features such as excellent mechanical properties, natural radiolucency, lack of toxicity and MRI compatibility ${ }^{10)}$. Another salient characteristic of PEEK is its lower elastic modulus which is essential in the distribution of stresses to the cortical bone. Many studies have evaluated the biocompatibility of PEEK as a biomaterial. However, studies are evaluating the wear resistance of milled PEEK, and its application as provisional material for implant-supported restoration are sparse.

Indirect composite resin-based restoration is an alternative to all-ceramic restoration for the aesthetic treatment of posterior teeth. They are essentially a composite filler matrix with different filler components. Fillers are added to improve some of the physical and chemical properties $^{11}$. The primary type of filler materials is glass, glass-ceramics, silicates and silicon dioxides. SR Adoro is a urethane dimethacrylate based indirect composite resin that offers distinct advantages over the conventional composite resin regard to wear, handling, plaque resistance and surface loss. The enhancement of the properties can be related to the high proportion of inorganic fillers in the nanoscale range ${ }^{11)}$.

Occlusal wear produces a change in the surface texture of the substrate material, which eventually influences the longevity of the restoration. Although 2-D surface profilometry is a routine method of a quantitative assessment of surface roughness the concept 3-D surface profilometry is developed recently. In the literature, studies utilising 3-D surface texture assessment before and after wear test is sparsely documented ${ }^{9,15)}$.

A wear testing machine simulates the masticatory cycle both functional and parafunctional, which allows analysis of two-body and three-body wear process and has been used in various in vitro studies to evaluate the effect of wear resistance of different substrate materials against an antagonistic tooth ${ }^{9,15)}$. Observation of the surface topography under different magnifications using light microscopy and scanning electron microscopy (SEM) are avail- able in earlier studies. The substrate materials or the tested samples are visualised under magnification for qualitative assessment ${ }^{6,18,19)}$. Studies evaluating the wear resistance of various biomaterials such as gold, amalgam, ceramics, acrylics are all well recognised. Studies comparing the wear parameters of milled PEEK material along with quantitative and qualitative surface analysis are not available.

It is categorically proven that superior mechanical properties are an essential prerequisite for the longevity of the prosthesis. Thus, testing the wear resistance of different materials used in the fabrication of provisional implant-supported restorations justifies the clinical scenario and requires detailed research ${ }^{7}$. Pin-on-disc wears testing machine used in this present in vitro study. The pin portion represented by mandibular first premolar tooth and the disc portion corresponded to the test materials. In some studies, the test materials are positioned in the holder and the antagonist tooth on the disc assembly ${ }^{15}$. Furthermore, some authors have suggested the flattening of the cusp tip ${ }^{20)}$.

In the present study, the tooth is made to contact at a single point, i.e. through the buccal tip alone. A total of 30 test samples were prepared and were grouped as GROUP I, GROUP II, GROUP III, each containing 10 test samples, respectively. GROUP I test samples consisted of milled PMMA material, GROUP II consisted of milled PEEK material, and GROUP III test samples consisted of SR Adoro materials. Thirty extracted mandibular first premolar teeth were selected as pins for wear test against three different provisional materials. The wear testing procedure is developed to simulate the wear process that occurs in the mouth. The range of masticatory cycle for a given day range from 5,000 300,000 cycles.to simulate this condition, wear cycle is followed in this study as recommended by Shetty MS et al. ${ }^{21)}$. The 12 wear test was done at $25 \mathrm{~N}$ load at $750 \mathrm{rpm}$ for 5,000 cycles $^{21}$, and 750 rpm and the entire cycle lasted for 6 minutes and 32 seconds. Artificial saliva made to flow on the substrate surface during the rotation of the disc ${ }^{22}$. All the test samples and the antagonist's tooth specimens are weighed before and after the end of 5,000 cycles of wear test and the final weight noted and tabulated.

In the present study, 3-D surface roughness texture 
Table 1. Overall comparison between the respective before wear test mean surface roughness values $(\mathrm{Ra})$ of the three test groups and between the respective after wear test mean surface roughness values $(\mathrm{Ra})$ of the three test groups using One Way Analysis of Variance (ANOVA)

\begin{tabular}{ccccc}
\hline $\begin{array}{c}\text { One way } \\
\text { ANOVA }\end{array}$ & $\begin{array}{c}\text { PMMA } \\
\text { mean/SD }\end{array}$ & $\begin{array}{c}\text { PEEK } \\
\text { mean/SD }\end{array}$ & $\begin{array}{c}\text { SR Adoro } \\
\text { mean/SD }\end{array}$ & P-value \\
\hline $\begin{array}{l}\text { Before wear } \\
\text { test }\end{array}$ & $0.827 / 0.093$ & $0.479 / 0.066$ & $0.054 / 0.020$ & $<0.001^{*}$ \\
$\begin{array}{l}\text { After wear } \\
\text { test }\end{array}$ & $6.021 / 5.767$ & $1.194 / 1.305$ & $1.407 / 1.604$ & $0.007^{*}$ \\
\hline
\end{tabular}

* $P<0.05$, statistically significant.

analysis of all the test samples (GROUP I, II, III) were evaluated before and after the wear test using a 3-D surface profilometry. The mean surface roughness (Ra) for Groups I, II, III before wear test found to be $0.827,0.437$, and 0.455 respectively. The mean surface roughness of GROUPS I, II and III after wear test found to be 6.021, 1.194, 1.407 respectively. On overall observation of Ra values, the findings show that there is an increase in the $\mathrm{Ra}$ values for all the test groups after wear test when compared with pre wear test Ra value. The highest mean surface roughness value was exhibited by milled PMMA samples (GROUP I), followed by SR Adoro samples (GROUP III). The least mean surface roughness value shown by milled PEEK samples (GROUP II).

\section{GROUP I $>$ GROUP III $>$ GROUP II}

The increase in the amount of surface roughness obtained for milled PMMA could be based on the fact that it is made up of $99.5 \%$ PMMA Polymer making it more dense and hard. Another possible explanation is that milled PMMA in the absence of filler particles makes it more susceptible to surface abrasion ${ }^{9}$. As this was evidence by well-defined peaks and valleys when examined under advanced 3-D imaging following post wear test.The Ra value obtained with SR Adoro sample demonstrated the rougher surface than the milled PEEK surface. Due to the presence of the filler particles. The particle size has an impact on the wear resistance, since, the relatively large size of filler particles acted as voids in the resin matrix and thereby weakening the integrity of the matrix ${ }^{11)}$.

The surface topography of the milled PEEK exhibits surface roughness, but the Ra values are lesser than the
Table 2. Multiple comparison of the before wear test mean surface roughness values $(\mathrm{Ra})$ of the three test groups and the after wear test mean surface roughness values (Ra) of the three test groups using post-hoc tukey's HSD analysis

\begin{tabular}{llcc}
\hline & Groups & $\begin{array}{c}\text { Mean } \\
\text { difference }\end{array}$ & P-value \\
\hline Before wear test & I \& II & 0.348 & $<0.001^{*}$ \\
& I \& III & 0.782 & $<0.001^{*}$ \\
I \& \& III & 0.433 & $<0.001^{*}$ \\
& I \& II & 4.826 & $0.014 *$ \\
& I \& III & 4.613 & $0.019 *$ \\
& I \& III & 0.212 & 0.990 \\
\hline
\end{tabular}

* $P<0.05$, statistically significant.

milled PMMA and SR Adoro. The reason for the presence of low surface roughness is because the addition of inorganic fillers in the CAD/CAM blanks displays a reduced risk of porosities within the material. On comparison of the mean wear rate all the three groups GROUP I, II, III, it is found that the mean wear rate of SR Adoro samples are marginally higher as compared to milled PEEK and milled PMMA samples. It had been identified that clinically acceptable Ra value is $0.2 \mu \mathrm{m}$ for high performance polymers ${ }^{23)}$ involved in fabrication of prosthesis. Values above this increases the possibility of biofilm formation and below this value, there is no significant film formation ${ }^{23,24)}$.

In a previous study by Santing $\mathrm{HJ}$ et al. ${ }^{6}$, the wear rate of indirect composite material and milled PMMA material were tested, and the results showed lesser wear for indirect composite and higher wear rate for milled PMMA. This is in contrary to the results obtained in the present study. This could probably be attributed to the differences in the design of the study, materials utilised and study parameters. Since there is a paucity of studies pertaining to the present in vitro study, the results cannot be comparable. Wear rate depends on the weight of the material which is measured pre and post wear test and also the duration of the rate of wear (Table 1, 2).

The coefficient of friction between the test groups is compared. Coefficient of friction values that shows the relationship between the force of friction between two objects and the normal force between the objects. The value is calculated to evaluate the frictional resistance among the test groups and therefore, to quantify the wear resistance. On comparison of the mean coefficient of fric- 
Table 3. Overall comparison between the mean wear rates between Group I (milled PMMA disc), GROUP II (milled PEEK disc) \& GROUP III (SR Adoro disc) after wear test using One Way Analysis Or Variance (ANOVA)

\begin{tabular}{cccc}
\hline \multicolumn{1}{c}{ Group } & Mean & $\begin{array}{c}\text { Standard } \\
\text { deviation }\end{array}$ & P-value \\
\hline Milled PMMA & 0.000 & 0.009 & 0.120 \\
Milled PEEK & 0.010 & 0.015 & \\
SR ADORO & 0.011 & 0.016 & \\
\hline
\end{tabular}

*P<0.05, statistically significant.

Table 4. Overall comparison of mean coefficients of friction between Group I (milled PMMA disc), Group II (milled PEEK disc) \& Group III (SR Adoro disc) after wear test using One Way Analysis of Variance (ANOVA)

\begin{tabular}{lccc}
\hline \multicolumn{1}{c}{ Group } & Mean & $\begin{array}{c}\text { Standard } \\
\text { deviation }\end{array}$ & P-value \\
\hline Milled PMMA & 0.979 & 0.080 & $<0.001^{*}$ \\
Milled PEEK & 0.865 & 0.031 & \\
SR Adoro & 0.840 & 0.046 & \\
\hline
\end{tabular}

*P<0.05, statistically significant.

tion between the test groups, it was found that the results were statistically significant. On a further comparison between the groups, there were significant statistical values between GROUPS I and GROUP II (P - 0.001) and GROUP I and GROUP III (P - 0.000) (Table 3, 4). Rough surfaces, high loads and high sliding speeds have been shown to have a high coefficient of friction resulting in more significant wear.

The volume loss of the substrate materials has to be scrutinised as it is directly related to wear. In the present study group, II exhibited higher volume loss, followed by PMMA (GROUP I) and low volume loss by SR Adoro (GROUP III) test samples (Table 5). On general perusal of the results obtained in the present study, the GROUP I test samples exhibited higher values in surface roughness and coefficient of friction. This is in correlation with the highest $\mathrm{Ra}$ value obtained and qualitative assessment by SEM. Moreover, all the test samples display increase surface roughness after wear test, and the values could not be compared with the surface roughness of the antagonist's tooth. Since negligible wear was observed on the antagonist, this could not be considered for comparative analysis. Hence future studies have to be done taking into the consideration of the wear parameters of the tooth
Table 5. Multiple comparison of the mean co efficient of friction between Group 1 (milled Polymethylmethacrylate disc), Group II (milled Polyetheretherketone disc) and Group III (SR Adoro disc) after wear test using Post-hoc Tukey's HSD analysis

\begin{tabular}{ccc}
\hline Group & $\begin{array}{c}\text { Mean difference coefficient } \\
\text { of friction }\end{array}$ & P-value \\
\hline I-II & 0.114 & $0.001^{*}$ \\
I-III & 0.138 & $<0.001^{*}$ \\
I-III & 0.024 & 0.394 \\
\hline
\end{tabular}

*P<0.05, statistically significant.

enamel.

The influence of the surface roughness results indicates that even though the presence of the roughness was observed on all the test samples after wear testing, GROUP I samples showed significantly highest value as compared to both Groups II and III. This is of clinical concern since roughened surface acts as a nidus for biofilm formation and predisposing the surface to accelerated wear. So the selection of the biomaterial should be made cautiously based on the intended duration of the prosthesis function. On the computation of the results obtained for milled PEEK and SR Adoro, the coefficient of friction and wear rate was found to be insignificantly different on statistical analysis. However, the surface roughness of PEEK samples was found to be significantly lesser than that of SR Adoro samples. The results derived from the quantitative surface roughness test groups are in concurrence with the observations in the SEM analysis. Thus the null hypothesis was rejected because of significant differences in test outcomes.

The present study has some limitations. The study conducted is two-body wear and not three-body wear. Hence situations replicating clinical scenarios and different masticatory cycles should be included in the future study. The effect of thermocycling was not evaluated in the study, as the samples were only soaked in artificial saliva 24 hours before the wear test. Hence proper protocol for thermocycling should be done in subsequent studies for predictable results. Future studies incorporating these parameters, including larger sample size, are recommended to add merit to the results obtained with the present study. 


\section{CONCLUSIONS}

Within the limitations of the present study, the following conclusions are drawn. Milled PMMA exhibited significantly highest surface roughness both before and after wear test as compared to both milled PEEK and SR ADORO materials. Milled PMMA showed significantly higher wear as compared to both milled PEEK and SR ADORO materials, indicative of least wear resistance among the test materials.Milled PEEK exhibited a marginally smoother surface compared to SR ADORO. Milled PEEK and SR ADORO showed marginal differences in wear resistance, indicative of similar wear resistance of these two test materials.

\section{ORCID}

Jayakrishnakumar Sampathkumar, https://orcid.org/0000-0003-0047-1999

Hariharan Ramakrishnan, https:/ / orcid.org/0000-0003-4466-5744

\section{REFERENCES}

1. Santosa RE. Provisional restoration options in Implant Dentistry. Aus Dent J 2007;52:234-42.

2. Wassel RW, Mccabe JF, Walls AWG. Wear characteristics in two- bodywear test. Dent Mater 1994;10:269-74.

3. Prasad DK, Shetty M, Alva H, Prasad DA. Provisional restorations in prosthodontic rehabilitations-concepts, materials and techniques. Nitte University Journal of Health Science 2012;2:72-7.

4. Wang WCW, Hafez TH, Almufleh AS, Ochoa-Durand D, Manasse M, Froum SJ, et al. A guideline on Provisional Restorations for Patients Undergoing Implant Treatment. J Oral Biol 2015;2:1-7.

5. Abishek. provisional restorations in Implant Dentistry Current Perspectives. Indian J Dent Sci 2015;1:131-4.

6. Santing HJ, Kleverlaan CJ, Werner A, Feilzer AJ, Raghoebar GM, Meijer HJA. Occlusal wear of provisional implant-supported restorations. Clin Implant Dent Relat Res 2015;17:179-85.

7. Presis V, Behr M, Kolbeck C, Hahnel S. Wear performance of substructure ceramics and veneering porcelains. Dent Mater J 2011;27:796-804.

8. Stawarczyk B, Eichberger M, Uhrenbacher J, Wimmer T, Edelhoff, Schmidlin PR. Three-unit reinforced polyetheretherketone composite FDPs: Influence of fabrication method on load-bearing capacity and failure types. Dent Mater J 2015;34:1-12.

9. Stawarczyk B, Ozcan M, Trottmann A, Schmutz F, Roos M, Hammerle C. Two-body wear rate of CAD/CAM resin blocks and their enamel antagonists. J Prosthet Dent 2013;109:325-32.

10. Stawarczyk B, Hum RB, Dipllng, Jordan P, Schmidlin PR, Roos $M$, et al. PEEK surface treatment effects on tensile bond strength to veneering resins. J Prosthet Dent 2014;112: 1278-88.

11. Culhaoglu AK, Park J. A comparison of wear resistance and hardness of two different indirect composite resins with the ceramic material, opposed to human enamel. E J Gen Dent 2013; 2:274-80.

12. Heintze S.D. How to qualify and validate wear simulation devices and methods. Dent Mater J 2006;22:712-34.

13. Lambrecht P, Dcbels E, Landuyt KV, Peumans M, Mcerbcck BV. How to simulate wear? Overview of existing methods. Dent Mater J 2006;22:693-701.

14. Zhou ZR, Yu HY, ZhengJ, Qian LM. Clinical Evaluation and Laboratory Wear-Testing Methods. Dental Biotribology, Springer, New York 2013;31-42.

15. Sripetchdanond J, Leevailoj C. Wear of human enamel opposing zirconia, glass-ceramic and composite resin: An in vitro study. J Prosthet Dent 2014;112:1141-50.

16. Cuth JF, Silva AE, Beuer F, Edelhoff D. Enhancing the predictability of complex rehabilitation with a removable CAD/CAM-fabricated long-term provisional prosthesis: a clinical report. J Prosthet Dent 2012;107:1-6.

17. Ramamoorthi M, Verma V, Sheikh Z. Dental biomaterials and a novel Composite of Zirconia and Poly Ether Ether Ketone for dental Implants. Int Dent J Stud Res 2015;2:16-22.

18. Delong R, Pintado M.R, and Douglas W.H. The wear of enamel opposing shaded ceramic restorative materials: An in vitro study. J Prosthet Dent 1992;68:42-8.

19. Hahnel S, Behr M, Handel G, Rosentritt M. Two- Body Wear of Artificial acrylic and composite resin teeth in relation to antagonist material. J Prosthet Dent 2009;10:269-78.

20. Elmaria A, Goldstein G, Vijayaragavan T, Legeros RZ, Hittelman EL. An evaluation of wear when the enamel is opposed by various ceramic materials and gold. J Prosthet Dent 2006;96: 345-53.

21. Shetty MS, Shenoy k. An in vitro analysis of wear resistance of commercially available acrylic denture teeth. J Indian Prosthodont Soc 2010;10:149-53.

22. Hirano S, May KB, Wagner WC, Hacker $\mathrm{CH}$. In vitro wear of resin denture teeth .J Prosthet Dent 1998;79:152-5.

23. Bollen CML, Papaioannou W, Van Eldere J, Schepers E, Quirynen M, Van Steenberghe D. The influence of abutment surface roughness on plaque accumulation and peri-implant mucositis. Clin Oral Imp Res 1996;7:201-11.

24. Bürgers R, Gerlach T, Hahnel S, Schwarz F, Handel G, Gosau M. In vivo and in vitro biofilm formation on two different titanium implant surfaces. Clin Oral Implants Res 2010;21:156-64. 